\title{
Maternal Chronic III Health Negatively Affects Child Survival in a Poor Rural Population of Pakistan
}

R. Nuruddin, Department of Community Health Sciences, The Aga Khan University, Stadium Road, P.O. Box 3500, Karachi 74800, Pakistan; Department of Community, Occupational and Family Medicine, National University of Singapore MD3, 16 Medical Drive, Singapore 117597

L. Meng Kin, Department of Community, Occupational and Family Medicine, Yong Loo Lin School of Medicine, National University of Singapore MD3, 16 Medical Drive, Singapore 117597

W.C. Hadden, National Institute on Aging, Gateway, 2C212, 7201 Wisconsin Avenue, Bethesda, MD 20892 USA

I. Azam, Department of Community Health Sciences, The Aga Khan University, Stadium Road, P.O. Box 3500, Karachi 74800, Pakistan

Correspondence: Dr. Rozina Nuruddin, Department of Community Health Sciences, The Aga Khan University, Stadium Road, P.O. Box 3500, Karachi 74800, Pakistan, E-mail: rozina.nuruddin@aku.edu

\footnotetext{
Abstract

Pakistan ranks fourth globally in terms of absolute numbers of under-5 deaths. Although several determinants of child deaths have been identified, the possibility of an association between mother's health and under-5 deaths has not been assessed in Pakistan. We compared data on 106 deceased children 0-59 months old with those on 3718 live children, using a cross-sectional survey of 2276 households among 99 randomly selected villages in Thatta, a rural district of Pakistan. We examined the association between self-reported maternal health status and under- 5 deaths, using the SUDAAN statistical package to account for cluster sampling technique. Three models for logistic regression analysis were Model-1: demographic factors, Model-2: household socio-economic factors and Model3: demographic and household socio-economic factors. Mothers of deceased children were $60 \%$ more likely to report chronic illnesses than mothers of live children after controlling for child's age, mother's
} 
age and type of house (final Model-3 analysis) (adjusted odds ratio [aOR; 95\% confidence interval]: 1.6 $[1.01,2.5])$. The association of self-reported maternal ill health with under- 5 deaths in Thatta suggests the role of maternal health in child survival. Child survival strategies should include screening and treating mothers for common chronic illnesses. This is particularly important in a setting where only a quarter of chronically ill mothers seek care outside the home.

\section{Background}

A widely used analytical framework for child mortality proposed by Mosley and Chen (1984) identifies five sets of proximate determinants, which include maternal factors, environmental contamination, nutrient deficiency, injury and personal illness control. An alternative framework proposed by D'Souza and Bryant (1999) identifies six sets of determinants, including maternal, child, sociodemographic, socio-economic, behavioral and environmental factors. Even though maternal factors such as age, parity and birth interval are included in these theoretical frameworks, mother's health status has not been explicitly described as associated with childhood mortality.

An association between maternal health and child survival, though long appreciated, has been described in only two settings. In a rural area of Bwamanda, Northern Zaire, Broeck et al. (1996) reported a 4.8-times greater mortality in infants $0-3$ months old among mothers with more than one sign of chronic disease, compared with mothers without any sign of chronic disease (95\% confidence interval $[\mathrm{CI}]: 1.1,20.7)$. In rural Western India, Hirve and Ganatra (1997) found a four-times (95\% CI: $1.7,9.6)$ greater infant mortality and a three-times $(95 \% \mathrm{CI}: 1.7,5.6)$ greater under-5 mortality among mothers with a non-pregnant weight of less than or equal to $40 \mathrm{~kg}$, compared with those of more than $40 \mathrm{~kg}$. This association between poor maternal health and deaths among under-5 children has not been examined in Pakistan, despite a high prevalence of anemia (47\%) as evidence of poor health status in rural Pakistani women of reproductive age (15-44 years) (Pakistan Medical Research Council [PMRC] et al. 1998).

Worldwide, Pakistan ranks fourth by number of under- 5 child deaths in a year (Robert et al. 2003) and 47th in descending order by under-5 mortality rate (United Nations Children's Fund [UNICEF] 2005). Pakistan's under-5 mortality rate is the highest among the South Asian countries (High Commission of Pakistan 2003) and exceeds the average for low-income countries by 60\% (World Bank Group 1998). In order to achieve the Millennium Development Goal 4, Pakistan aims to reduce its under-5 mortality rate from around 140/1000 live births in 1990 to around $50 / 1000$ live births by 2015 (Planning Commission of Pakistan 2004).

Currently, a number of child-survival programs have been implemented by the World Health Organization (WHO; Expanded Programme of Immunization - EPI, Control of Diarrhoeal Diseases - CDD and acute respiratory infections - ARI) and UNICEF (growth monitoring, oral rehydration, breastfeeding promotion and Immunization-GOBI and Integrated Management of Childhood Illnesses - IMCI). In spite of these efforts, however, Pakistan's under-5 mortality rate (100/1000 live births) remains unacceptably high (WHO 2006a). Hence, locally relevant factors associated with child mortality need to be examined and incorporated in child-survival programs.

Data from a large community survey in a rural district of Sindh, Pakistan, provides an opportunity to examine whether mother's health is associated with child survival. We hypothesize that poor maternal health is associated with high under-5 mortality.

\section{Material and Methods}

\section{Study Site}

Thatta is a predominantly rural district located 60 kilometres east of Karachi, in the southernmost part of Sindh province, the second largest province of Pakistan. There are 49 administrative units (called union councils) and 6614 village settlements in Thatta (Government of Sindh and UNICEF 1993). Children aged 5 years and below make up $16 \%$ of Sindh's population of 2 million. Indicators of health status reflect the population's poor health and the inadequacy of the healthcare 
system. Indicators include a high maternal mortality ratio (800/100,000 live births), low immunization coverage ( $46 \%$ complete immunization for children under 3 years of age), high total fertility rate (7.5) and low contraceptive prevalence (3.3\%) (Department of Community Health Sciences [DCHS] 1994).

\section{Data Source and Survey Design}

The data analyzed here were collected in a survey by the Research Information System (RIS) of the Thatta Health System Research Project of The Aga Khan University, Karachi, from November 1992 to February 1993, after obtaining approval from the Institutional Ethical and Review Committee (DCHS 1994). The survey served as a baseline in a research project aimed at evaluating interventions in the government health system implemented at district, primary healthcare unit and community levels. Villages (Primary Sampling Units) located within a radius of 5 kilometers of 12 different Government Health Facilities (GHFs) (9 intervention and 3 reference health facilities) were listed and mapped to provide a sampling frame for the first-stage sampling. Villages (5 to 12) were randomly selected from each service area, with a target to sample at least 250 households per GHF catchment area. In this way, 99 villages were selected, serving as clusters. Within these selected clusters, all 2276 households (Secondary Sampling Units) were surveyed.

\section{Data Collection}

Interviewers (20), supervisors (four) and a survey manager were trained through a 3-week fieldbased program. A pre-coded questionnaire was pre-tested for ease and accuracy of data collection. Trained interviewers visited each household, with the assistance of village volunteers, and conducted the survey after securing informed consent. Completed questionnaires were checked and validated by field supervisors daily.

Household heads (or in their absence, the next elder/responsible member of the household) provided information on socio-demographic characteristics of households and their members. A complete reproductive history was obtained from mothers by asking about the number of times they had been pregnant, had live deliveries and still births, the number of live children, and when the last delivery was and its outcome. Children's ages were estimated with the aid of local event calendars listing important events, festivals and moon cycles in the last 5 years. If there had been a death in the household during the last year, information was collected regarding age and sex of the deceased and probable cause of death. Mothers and fathers were asked whether they had been ill during the last year. Those who reported illness were asked an additional series of questions about symptoms, probable cause and duration of illness, and source of care. Interviewers were trained to code common chronic illness from the reported symptoms.

\section{Study Design}

This is a cross-sectional study analyzed as a case-control study. We studied all children aged 0-59 months, including those who had died in the last year. Index series are defined as children under 5 years of age who died during the year prior to the survey. Reference series are subjects of similar age to those in the index series and who were alive at the time of interview.

\section{Variables}

Five mortality ratios were calculated according to WHO standards (WHO 2006b; Nathan et al. 2002). For each ratio, the number of live births in a year expressed per 1000 served as the denominator. The numerator varied for each ratio as the number of deaths among neonates (newborn to 29 days old), post-neonates (1-11 months old), infants (newborn to completed 11 months old), early childhood (12-59 months old) or under 5 (newborn to 59 months old). These ratios are traditionally referred to as neonatal, post-neonatal, infant, early childhood and under- 5 mortality rates (WHO 2006b; Nathan et al. 2002). 


\section{Main Independent Variable}

The main independent variable, self-reported by mothers, was the presence or absence of illnesses that lasted for more than 2 weeks and occurred during the year prior to the survey. Mothers reporting such illnesses were classified as chronically ill.

\section{Other Independent Variables}

(a) Demographic variables included (i) child's age (grouped as newborn to 11 months and 12-59 months), (ii) gender, (iii) mother's age (grouped as 30 years or less and above 30 years), (iv) chronic illnesses in father (as defined for mother), (v) number of siblings in the family (categorized as three or less and four or more) and (vi) number of adults (persons older than 18 years of age) in the household (as a proxy measure of alternative care providers, categorized as two or less and three or more).

(b) Household socio-economic factors were assessed by (i) average monthly income per capita (categorized as less than 200 Pak. Rupees [6.5 US dollars] or 200 Pak. Rupees and more), (ii) mother's literacy status (ability to read and/or write a short simple statement), (iii) father's literacy status (as defined for mother), (iv) housing construction material (made of concrete or non-concrete, such as mud, stone or wood) and (v) land ownership.

\section{Data Management and Analysis}

Data were checked for internal consistency before entry. Questionnaires with inconsistencies were returned to the field for correction. The data were double entered using Borland dBase III Plus 1.1 for DOS Version XX.X computer software and checked for obvious errors of data entry and editing. An error rate of less than 3/1000 strokes was considered clean data entry. Analysis was performed with SUDAAN Release 9.0. due to its computational efficiency and to account for cluster survey design in point and variance estimation.

The statistical power of detecting a difference in under- 5 mortality in the presence or absence of self-reported mother's chronic illness was estimated as $83 \%$, assuming an unadjusted odds ratio of 1.90 and prevalence of mother's illness among live children was 20\% (NCSS statistical package: Power Analysis \& Sample Size, Version XX.X).

To account for unequal selection probabilities, we calculated sample weights from the number of villages in each service area and the number of villages sampled from each area. The use of weights reduces bias in estimation. Keeping in view without replacement (WOR) sampling design, we present weighted estimates of mortality and odds ratios and their 95\% CIs.

Multi-collinearity among various independent variables was also assessed using Cramer's V. Three models constructed for logistic regression to examine association between mother's health and child death consisted of the following covariates:

Model-1: Demographic variables

Model-2: Household socio-economic factors

Model-3: Demographic and household socio-economic factors

In each model, after examining the full set of variables, non-significant variables were dropped from the final. We present the results of final models.

\section{Results}

\section{Characteristics of the Study Population}

Among 3824 children, infants constituted almost a quarter $(22.5 \%)$ of the study population. Overall, boys and girls were almost equally distributed ( $50.6 \%$ and $49.4 \%$, respectively). The mean age of mothers was 30.0 years $(S E=0.12$ years). Mean numbers of siblings in a family and mean 
number of adults in a household were $4.3(S E=0.04)$ and $3.3(S E=0.04)$, respectively. Both average (median) monthly income (only 1415 Pak. Rupees or 47.2 US dollars, 1993) and average (median) monthly per capita income (only 193 Pak. Rupees or 6.4 US dollars, 1993) were low. Considerably more mothers $(84 \%)$ than fathers $(54 \%)$ were illiterate. One third of households reported owning some land (35\%). A majority lived in non-concrete houses (83\%).

Overall, $20.2 \%$ and $17.7 \%$ of mothers and fathers, respectively, reported being ill for more than 2 weeks during the last year. Among mothers defined as chronically ill (725), 40.3\% reported weakness/anemia, $19.3 \%$ were classified with respiratory illness including tuberculosis and asthma, $12.6 \%$ with jaundice/hepatitis, $8.4 \%$ with kidney problems, $7.7 \%$ with diabetes, $5.9 \%$ with skin infections/scabies, $1.4 \%$ with fever/malaria and the remaining $4.4 \%$ with illnesses other than those listed above. The proportion of child deaths differed significantly by child's age, gender, maternal health status and type of house (Table 1).

Table 1. Significant factors by survival status, Thatta District, Pakistan, 1992-1993 $(\mathrm{n}=3824$ ) (unadjusted analysis)

\begin{tabular}{|c|c|c|c|}
\hline Variables & Groups $(n)$ & Deaths (\%) & $\begin{array}{l}\text { Odds Ratio } \\
(95 \% \text { CI) }\end{array}$ \\
\hline $\begin{array}{l}\text { Child's age } \\
\text { Child's gender } \\
\text { Maternal health status } \\
\text { Type of house }\end{array}$ & $\begin{array}{l}\text { Infants (862) } \\
\text { 1-4 years (2962) } \\
\text { Female (1902) } \\
\text { Male (1922) } \\
\text { Reported ill (725) } \\
\text { Reported not ill (2874) } \\
\text { Non-concrete (3118) } \\
\text { Concrete (632) }\end{array}$ & $\begin{array}{l}8.9 \\
1.0 \\
3.4 \\
2.2 \\
4.4 \\
2.4 \\
2.9 \\
1.5\end{array}$ & $\begin{array}{l}9.6(6.7,13.6) \\
1.00 \\
1.5(1.05,2.20) \\
1.00 \\
1.9(1.2,2.8) \\
1.00 \\
1.9(1.1,3.5) \\
1.00\end{array}$ \\
\hline
\end{tabular}

\section{Age-Specific Death Ratios}

During the year prior to the survey, 106 children aged 0-59 months died, accounting for $43.4 \%$ of total deaths (244). Of the 996 live births during the same period, 508 were males. Infant deaths constituted $72.6 \%$ of child deaths, and neonatal deaths accounted for $39 \%$ of infant deaths (Table 2).

Table 2. Age-specific mortality ratios: Thatta District, Pakistan, 1992-1993

\begin{tabular}{|l|l|l|}
\hline Age Group & Number of Deaths & Mortality Ratio (Deaths per $\mathbf{1 0 0 0}$ Live Births in a Year) (95\% CI) \\
\hline Neonates & 30 & $30.6(21.4,39.8)$ \\
Post-neonates & 47 & $47.0(32.2,61.8)$ \\
Infants & 77 & $77.7(57.8,97.5)$ \\
12-59 months & 29 & $30.4(19.7,41.1)$ \\
0-59 months & 106 & $108.1(82.6,133.5)$ \\
\hline
\end{tabular}

\section{Association between Mother's Health and Child Mortality}

Unadjusted analysis suggested that children of mothers with reported chronic illness were $90 \%$ more likely to die compared with children whose mothers did not report chronic illness (critical odds ratio [cOR; 95\% CI]: 1.9 [1.2, 2.8]) (Table 1). After simultaneous adjustment of demographic and socio-economic factors in the final Model-3, although the association of mother's health with under- 5 mortality dropped to $60 \%$, it remained significant (Table 3 ). 
Table 3. Association between maternal health and child mortality: Thatta District, Pakistan, 1992-1993

\begin{tabular}{|l|c|c|c|}
\hline Variables & \multicolumn{3}{c|}{ Adjusted Odds Ratio (95\% CI) } \\
\hline & Final Model-1 & Final Model-2 & Final Model-3 \\
\hline Chronically ill mother & $1.9(1.2,2.9)$ & $1.8(1.2,2.7)$ & $1.6(1.01,2.5)$ \\
Child's age & $9.1(6.5,12.9)$ & - & $9.9(6.6,15.0)$ \\
Child's gender & $1.6(1.1,2.4)$ & - & - \\
Mother's age & - & - & $1.5(1.1,2.2)$ \\
Non-concrete house & - & $2.0(1.1,3.5)$ & $2.0(1.1,3.7)$ \\
\hline
\end{tabular}

List of non-significant variables dropped from final models

Model-1: (i) Chronic illnesses in father (ii) Number of siblings in the family and (iii) Number of adults in the family.

Model-2: (i) Average monthly income per capita (ii) Mother's literacy status (iii) Father's literacy status and (iv) Land ownership.

Model-3: (i) Child's gender (ii) Chronic illnesses in father (iii) Number of siblings in the family (iv) Number of adults in the family (v) Average monthly

income per capita (vi) Mother's literacy status (vii) Father's literacy status and (viii) Land ownership.

\section{Other Associations with Child Mortality}

Besides child's age, the final Model-3 analysis showed an association of child mortality with mother's age and type of house. Children whose mothers were 30 years or older were $50 \%$ more likely to die compared with children of younger mothers. In addition, children who lived in non-concrete houses were twice as likely to die as children who lived in concrete houses (Table 3).

\section{Discussion}

\section{Main Study Findings}

The observed association between self-reported maternal ill health and under-5 mortality could be due to reduced maternal ability for child-rearing activities, reduced duration of breastfeeding, low birth weight, increased childhood malnutrition, increased child morbidity and reduced utilization of services for curative or preventive care.

As expected, child's age remained the most powerful determinant of child's survival. We identified two more associations with under-5 mortality in Thatta district, namely mother's age of 30 years or above and living in non-concrete houses. Greater mortality associated with older mothers could possibly be due to the increasing number of children and subsequent demand on the mother's physical strength for child rearing, as shown by a highly significant association between maternal age and number of live children. Mothers 30 years and older were 8.4 times more likely to have four or more children than were younger mothers (OR [95\% CI]: $8.4[6.5,10.8]$ ) (result of a separate analysis). Living in a non-concrete house was also associated with $90 \%$ greater under-5 mortality, which could be either a reflection of low socio-economic or poor environmental conditions.

\section{Earlier Work on the Topic}

The relationship between maternal health and deaths among the specific age group of children 0-59 months has not been studied in Pakistan. In a rural area of Bwamanda, Northern Zaire (Broeck et al. 1996), a prospective study revealed an association between maternal health and death among infants 0-3 months old. Compared with Northern Zaire, the magnitude of the association is relatively small in Thatta district. This could be due to difference in age distribution of study populations and instruments used to assess chronic diseases in the two surveys. In Northern Zaire, chronic maternal disease was assessed by clinical examination and by history. Prevalence of chronic maternal disease was much less in Northern Zaire (3.1\%) than in Thatta (20.2\%). Due to variations in living and 
environmental conditions between the settings, different sets of covariates were examined in the two studies through different analytical approaches. In rural Western India, Hirve and Ganatra (1997) considered maternal health status as poor if the mother's non-pregnant weight was less than or equal to $40 \mathrm{~kg}$. In this prospective study, the survival analysis showed a strong association of maternal nutritional status and under-5 mortality. Although we have defined maternal health status subjectively, based on self-reporting of illness, the findings of our study, though lower in magnitude, are consistent with other studies (Broeck et al. 1996; Hirve and Ganatra 1997). These findings are also important since ours is the first such study from Pakistan, a country with a high under-5 mortality ratio (WHO 2006a) and high prevalence of poor maternal health (PMRC et al. 1998).

The observed magnitude of the association between under- 5 mortality and child's age $(\mathrm{OR}=$ 9.9) is similar to that reported in rural Upper Egypt $(\mathrm{OR}=10)$ by Yassin (2000). Despite using a different age cut-off (20 years) for mothers than ours (30 years), Ahmed (1992) reported lower child mortality for young rural mothers, using the Pakistan Contraceptive Prevalence Survey (1984-85). Other studies from Pakistan using information from the Pakistan Integrated Household Survey 1991 (Agha 2000), the Pakistan Demographic and Health Survey, 1990-91 (Ali et al. 1993; Zahid 1996), and the Pakistan Labor Force and Migration Survey, 1979 (Sathar 1987), reported higher infant death rates among mothers less than 20 years. We did not choose a cut-off at age 20 , as only $8.3 \%$ of the mothers reported being 20 years or below. In Karachi slums, no association was reported between maternal age and infant or child death (D'Souza and Bryant 1999; Thaver et al. 1990). This suggests that the relationship between maternal age and child survival for rural populations differs from other areas of the country. In a rural population, older mothers have greater rates of child mortality than younger mothers.

The association between type of house and under-5 mortality was stronger in our population than in that reported for Zimbabwe (Root 1997), where households with clay flooring had $47 \%$ (95\% CI: 1.06, 2.05) greater mortality for children $1-5$ years old compared with households with cement flooring. However, using information from the Pakistan Integrated Household Survey 1991, Agha (2000) did not find any significant relationship between type of house and infant mortality. This suggests that observations from a rural population of Sindh are different from those from a national sample.

\section{Study Limitations}

Certain methodological issues need to be highlighted. Though death, being a definitive event, is easily measured, the possibility of under-reporting cannot be ruled out. Women are at times reluctant to talk about their dead children or may not count children dying shortly after birth as live births, which would affect estimates of the mortality ratio. Using reported age at death or at survey without reference to exact dates of birth and death results in misclassification or age heaping across the boundaries of 1 month, 1 year and 5 years.

The method of assessing maternal health deserves special consideration. Timing of measurement in this study does not ensure that maternal illness occurred prior to the death of the child. Since both the child death and maternal illness were assessed during a 1-year period prior to the survey, it is possible that maternal illness might have occurred after the death of the child. This makes causality difficult to establish. Assessment of maternal health by self-report could account for non-differential misclassification of exposure status and under-estimation of the effect (Rothman and Greenland 1998). Moreover, defining chronic diseases as those of more than 2 weeks' duration includes diseases of varying severity, making interpretation difficult.

Characteristics of parents and households were assessed at the time of survey and not when the children under study were exposed to risk of death. However, it is unlikely that factors such as socio-economic status had changed significantly over a 1-year period for the majority of the study population. For factors such as income, inaccuracy in reporting cannot be ruled out. Creation of a wealth variable might have addressed this problem, but it was not possible due to lack of such information. We did not account for nutritional status of mothers and deceased children's birth 
weights because the information was not available, although they could possibly be associated with chronic maternal illness and child survival (Hirve and Ganatra 1997).

Inclusion of villages located within a radius of 5 kilometers of the selected GHFs may influence the extent to which the findings can be generalized, as child mortality ratios and maternal health status may be worse in far-off villages.

\section{Conclusion: Policy Implications}

Currently, local child-survival programs focus on control of diarrhea, acute respiratory infections, malnutrition and vaccine-preventable diseases and ignore the important contribution of maternal health to child survival (Bhutta 2004). Promotion of mother's health, particularly prevention and treatment of anemia, though encouraged during antenatal, natal and postnatal periods, is not performed beyond the postpartum period. This study points out that child-survival programs should include activities leading to the promotion of mother's health beyond pregnancy and postpartum. This is particularly relevant in the underprivileged area of Thatta, where only a quarter of mothers with chronic illness report receiving treatment at a government or private health centre. Whenever a mother comes in contact with the healthcare system (e.g., for routine vaccination of her child), she should be opportunistically screened and treated for common conditions such as anemia, undernutrition or chronic cough. These study findings need to be tested further by studies in which maternal health is assessed objectively, with an etiologically relevant induction period.

\section{Acknowledgments}

Authors are thankful to Dr. Chan Yiong Huak for providing technical assistance during data organization and to Dr. Gregory Pappas for critically reviewing the manuscript. Funding support for this project was provided by the International Development Research Centre (IDRC), Canada.

\section{Competing Interests}

The authors declare that they have no competing interests.

\section{Author's contributions}

$\mathrm{RN}$ participated in the design of survey, conceived and designed the study, performed the literature review and data analysis, interpreted the data and drafted and revised the manuscript.

LMK provided guidance during study design and data interpretation and in revising the paper critically for important intellectual content.

WCH provided guidance during data analysis and data interpretation and in revising the paper critically for important intellectual content

IA participated in the data organization and in revising the paper critically for substantial intellectual content.

All authors read and approved the final manuscript.

\section{References}

Agha, S. 2000. “The Determinants of Infant Mortality in Pakistan.” Social Science \& Medicine 51: 199-208. Retrieved August 12, 2006. <http://www.ncbi.nlm.nih.gov/entrez/query.fcgi?.cmd=Retrieve\&db=PubMed\&d opt $=$ Citation\&list_uids $=10832568>$

Ahmed, T. 1992. "Factors Associated with Child Mortality in Pakistan and Implications for the National Health Programs." Asian and Pacific Population Forum 6: 29-34, 53-8. Retrieved April 1, 2006. <http://www. ncbi.nlm.nih.gov/entrez/query.fcgi?cmd=Retrieve\&db=PubMed\&dopt=Citation\&list_uids=12285495> 
Ali, S.M., H.B. Siyal and M. Sultan. 1993. "How Similar Are the Determinants of Mortality and Fertility?" Pakistan Development Review 32: 1107-1115. Retrieved July 11, 2006. <http://www.ncbi.nlm.nih.gov/entrez/ query.fcgi? $\mathrm{cmd}=$ Retrieve $\& \mathrm{db}=$ PubMed $\& \mathrm{dopt}=$ Citation\&list_uids=12346809>

Bhutta, Z.A. 2004. "Beyond Bellagio: Addressing the Challenge of Sustainable Child Health in Developing Countries." Archives of Disease in Childhood 89(5): 483-487.

Broeck, J.V.D., R. Eeckels and G. Massa. 1996. "Maternal Determinants of Child Survival in a Rural African Community." International Journal of Epidemiology 25: 998-1004.

Department of Community Health Sciences [DSHS], The Aga Khan University, Karachi. 1994. Thatta Health System Research Project, Phase III Year 2 Report. Karachi: The Aga Khan University.

D’Souza, R.M. and J.H. Bryant. 1999. "Determinants of Childhood Mortality in Slums of Karachi, Pakistan.” Journal of Health \& Population in Developing Countries 2: 33-44. Retrieved June 9, 2006. <http://www.ncbi. nlm.nih.gov/entrez/query.fcgi? $\mathrm{cmd}=$ Retrieve $\& \mathrm{db}=\mathrm{PubMed} \& \mathrm{dopt}=$ Citation\&list_uids=12349108>

Government of Sindh and United Nations Children's Fund. 1993. Situation Analysis of Children and Women in Sindh. Karachi: Government of Sindh and UNICEF.

High Commission of Pakistan [HCP]. 2003. Health Chapter for Pakistan. State of Human Rights in 2003, pp. 330-331. Islamabad: HCP.

Hirve, S. and B. Ganatra. 1997. "A Prospective Cohort Study on the Survival Experience of under Five Children in Rural Western India." Indian Pediatrics 34: 995-1001.

Mosley, W.H. and L.C. Chen. 1984. "An Analytic Framework for the Study of Child Survival in Developing Countries." Population and Development Review 10: 25-45.

Nathan, R., H. Becher and A. Razzaque. 2002. "Chapter 2. DSS-Generated Mortality Rates and Measures." In O.A. Sankoh, K. Kahn, E. Mwageni, P. Ngom and P. Nyarko, eds., Population and Health in Developing Countries. Population, Health, and Survival at Indepth Sites. Ottawa: International Development Research Centre. Retrieved August 12, 2006. <http://www.idrc.ca/careers/ev-42994-201-1-DO_TOPIC.html>

Pakistan Medical Research Council, Federal Bureau of Statistics and Department of Health and Human Services. 1998. National Health Survey of Pakistan: Health Profile of People of Pakistan, 1990-94 pp. 170-173. Islamabad: PMRC, FBS and DHHS.

Planning Commission of Pakistan [PCP]. 2004. Pakistan Millennium Goals Report. Islamabad: PCP. Retrieved October 29, 2006. <http://www.mopd.gov.pk/usefull\%20links/Economics/mdgr.pdf>

Robert, E.B., S.S. Morris and B. Jennifer. 2003 .”Where and Why Are 10 Million Children Dying Every Year?” The Lancet 361: 2226-2234.

Root, G. 1997. "Population Density and Spatial Differentials in Child Mortality in Zimbabwe." Social Science \& Medicine 44: 413-21.

Rothman, K. and S. Greenland. 1998. Modern Epidemiology. Philadelphia, Baltimore, New York, London, Buenos Aires, Hong Kong, Sydney, Tokyo: Lippincott, Williams and Wilkins, A Wolters Kluwer Company.

Sathar, Z.A. 1987. “Seeking Explanations for High Levels of Infant Mortality in Pakistan.” Pakistan Development Review 26: 55-70. Retrieved September 13, 2006. <http://www.ncbi.nlm.nih.gov/entrez/query.fcgi?cmd=Retr ieve\&db=PubMed\&dopt=Citation\&list_uids $=12341420>$

World Bank Group [WBG]. 1998. South Asia Brief: Raising a Healthier Population in Pakistan. Washington DC: WBG. <http://lnweb18.worldbank.org/sar/sa.nsf/Attachments/pakistan-health/\$File/pakistan-health.pdf>

Thaver, I. H., G.H. Ebrahim and R. Richardson. 1990. "Infant Mortality and under Nutrition in the Squatter Settlements of Karachi." Journal of Tropical Pediatrics 36: 135-140.

United Nations Children's Fund [UNICEF]. 2005. Multiple Indicator Cluster Surveys. New York: UNICEF. Retrieved December 18, 2006. <http://www.unicef.org/infobycountry/pakistan_pakistan_statistics.html>

World Health Organization. 2006a. World Health Report. Geneva: WHO. Retrieved March 21, 2006. <http:// www.who.int/countries/pak/en/>

World Health Organization. 2006b. Who Indicators, Definitions and Metadata. Geneva: WHO. Retrieved November 24, 2006. <http://www.who.int/whosis/whostat2006DefinitionsAndMetadata.pdf>

Yassin, K.M. 2000. "Indices and Socio-Demographic Determinants of Childhood Mortality in Rural Upper Egypt." Social Sciences and Medicine 51: 185-97.

Zahid, G.M. 1996. "Mother's Health-Seeking Behaviour and Childhood Mortality in Pakistan.” Pakistan Development Review 35: 719-31. Retrieved March 12, 2006. <http://www.ncbi.nlm.nih.gov/entrez/query. fcgi? $\mathrm{cmd}=$ Retrieve\&db=PubMed\&dopt=Citation\&list_uids=12146446> 